\title{
Antifungal Activity of leaf extracts of Nerium indicum against Pathogenic Fungi Aspergillus spp.
}

\author{
Renu Jangid ${ }^{1}$, Tahira begum ${ }^{2}$ \\ ${ }^{1,2}$ Department of Botany, Samrat Prithviraj Chauhan Government College Ajmer, Rajasthan, India
}

Available online at: www.isroset.org

Received: 11/May/2019, Accepted: 20/Jun/2019, Online: 30/Jun/2019

\begin{abstract}
Medicinal plants represent a rich source of antimycotic agents. Plant extract has been used traditionally to treat a number of infectious diseases. Medicinal plant Nerium indicum belongs to the family Apocynaceae. The leaf extracts of Nerium indicum exhibited significant antifungal activity against pathogenic fungi (A. niger, A. flavus and A. fumigatus). Aspergillus species were isolated from soil samples. The soil samples collected from Ajmer, Rajasthan (India). Antifungal activities of the different leaf extracts were compared with the zones of inhibition produced by the standard antibiotic (Gresiofulvin). The ethanol, aqueous and DMSO extracts of Nerium indicum showed high antifungal activity against Aspergillus species except ethanol extract show lowest activity against A. niger. These results support the leaf extract of Nerium indicum can be used to cure fungal infections in both plant and human beings.
\end{abstract}

Keywords: Plant extracts, Disc diffusion, Antifungal activity, Aspergillus species.

\section{INTRODUCTION}

Medicinal plants are represent a rich source of antifungal agent and are traditionally used for the treatment of infectious diseases. Plants and their products have been used since ancient times for medicinal purpose. According to a report by the WHO (World Health Organization) 20,000 plant species are currently in use for medicinal purposes [1]. Plant extracts has been used traditionally to treat a number of infectious disease including those caused by bacteria, fungi, protozoa and viruses. Microorganisms have developed resistance to many antibiotics and as a result, an immense clinical problem in the treatment of infectious diseases has been created [2]. Fungi are ubiquitous in the environment, and infection due to fungal pathogens has become more frequent [3, 4]. Research on new antimicrobial substances should be continued and small molecules from medicinal chemistry, as well as natural products are still major sources of innovative therapeutic agents for infectious disease [5]. Natural products are generally harmless or have minimum side effects as compared to synthesis drugs [6]. Aqueous and solvent extracts of different plant parts have been tested for pharmacological and therapeutic activities, such as antimicrobial, hepatoprotective and other activities [7]. Testing plant extracts for antifungal activity could be a good source to identify new antifungal drugs. The search for novel antifungal agents relies in great parts on ethno medicinal plants information and ethno pharmacologic exploration [8]. A vast array of diseases occurs due to the fungal infections such as athlete's foot, candidiasis, aspergillosis and zygomycosis, etc. Aspergillosis is an infection caused due to inhalation of Aspergillus spores. Aspergillus species are ubiquitous in organic matter such as hay, decaying vegetation, soil and construction sites. The types of health problems caused by Aspergillus include allergic reactions, lung infections, and infections in other organs. In plants also Aspergillus species cause harmful disease such as black rot, collar rot disease etc.

Nerium indicum is an important medicinal plant of family Apocynaceae and commonly known as "Kaner" in hindi and "Karabi" in Bengali. It grows upto 2-6m in height. Leaves are long, thick, leathery, simple, whorled, linear lanceolate, hairless, 9-14 $\mathrm{cm}$ in length with horizontal nerves. In medicinal plants Nerium indicum is one of the plants which are famed for its therapeutic efficiency in different disease globally. It is used as traditionally medicine in different parts of the world, especially in India and China. The Ethanol flower extracts of this plant were showed antifungal activity against different fungal pathogens [9]. In the present study, leaf extracts of Nerium indicum has been chosen for the investigation of in vitro antifungal activity against Aspergillus niger, Aspergillus fumigates, A. flavus.

The aim of this study was to assess the antifungal activity of leaf extracts of Nerium indicum against Aspergillus sp. From the above discussion were that the plant products have powerful antifungal properties, which can be used for the treatment and were the various ailments. 


\section{II.MATERIAL AND METHODS}

\subsection{Fungal Material}

Three Aspergillus fungi selected for antifungal activity. All three cultures were isolated from soil samples by Hair Baiting technique.

\subsection{Culture Media}

The isolated fungus was maintained on Sabouraud's Dextrose Agar medium.

\subsection{Plant Material}

The leaves of Nerium indicum were collected during spring and summer seasons (April-June, 2017.) in the local area of Ajmer district, Rajasthan and authenticated by Department of Botany, Samrat Prithviraj Chauhan Government College Ajmer, Rajasthan, India. The leaves were washed thoroughly 2-3 times with running water, blotted with filter paper and dried in the shade. After then dried material was ground into powder using blender and sealed in polythene bags for further use.

\subsection{Preparation of leaf extracts}

Plant extract was prepared by soxhlet extraction method. About $10 \mathrm{gm}$ of dried and powdered leaf material was uniformly packed in to a thimble and run in soxhlet extractor with ethanol/ DMSO for 48 hours. The extract was then filtered with the help of filter paper and solvent was evaporated from extract. For aqueous extraction, $10 \mathrm{gm}$ of powdered material was macerated by blender with $100 \mathrm{ml}$ of distilled water and solvent powder mixture was kept at room temperature for 48 hours, the extract was filtered through filter paper. The extracts were kept in refrigerator at $4^{0} \mathrm{c}$ for further experiments.

\subsection{Antifungal Activity}

Antifungal activities of the leaf extracts were determined, using the Disk diffusion method as described Kirby-Bauer (1956). Filter paper Discs of $6 \mathrm{~mm}$ diameter were soaked with $1 \mathrm{ml}$ of extracts. Sabouraud's Dextrose Agar plates were inoculated with each fungal culture by point inoculation. The plates were done in triplicates and were incubated at $27^{\circ} \mathrm{C}$. The antifungal activity was taken on the basis of diameter of zone of inhibition, which was measured after 7 days of incubation and the mean of three readings is presented.

\subsection{Control experiment}

The presence of inhibition of the treated fungus was calculated using Griseofulvin as standard.

\subsection{Statistical analysis}

The data were calculated as mean \pm SD and analyzed using one way analysis of variance (ANOVA).

\section{RESULTS}

The data on Aspergillus species isolated from soils of Ajmer district (Rajasthan). Antifungal activity of different extracts against pathogenic fungi (Aspergillus niger, A. flavus, and A. fumigates) was evaluated by the Disc diffusion method. The results and screening of antifungal activity of Nerium indicum leaf extracts are summarized in table 1. All the extracts tested exhibited different degrees of antifungal activity against $A$. niger, $A$. flavus and A. fumigates. Nerium indicum shown high antimycotic activity against all the tested fungus except $A$. niger. The percentage of growth inhibition of the selected pathogenic Aspergillus species by leaf extracts of Nerium indicum was recorded and the data were showed in table 2 . The percentage growth inhibition of pathogenic fungi by leaf extracts were data put in graph present in Fig.1. The graph showed that aqueous extract of Nerium indicum leaf exhibited strong antifungal against $A$. niger with inhibition zone of $16 \mathrm{~mm}$ diameter as compared with inhibition zone of $14 \mathrm{~mm}$ diameter produced by commercially available standard antibiotic (Griseofulvin). The lowest activity was recorded DMSO extract against $A$. flavus with inhibition zone of $16 \mathrm{~mm}$ diameter.

Table 1: Antifungal activity of different solvent extracts of Nerium indicum leaves.

\begin{tabular}{|l|c|l|l|}
\hline \multirow{2}{*}{ Extracts/drug } & \multicolumn{2}{|c|}{ Zone of inhibition (mm) } \\
\cline { 2 - 4 } & \multicolumn{1}{|c|}{ A. niger } & A. flavus & $16 \pm 1.16$ \\
\hline Ethanol & $08 \pm 0.58$ & $20 \pm 0.58$ & $18 \pm 0.58$ \\
\hline Aqueous & $16 \pm 1.16$ & $22 \pm 1.16$ & $20 \pm 0.58$ \\
\hline DMSO & $14 \pm 1.16$ & $16 \pm 0.58$ & $22 \pm 0.58$ \\
\hline Griseofulvin & $14 \pm 0.58$ & $24 \pm 1.16$ & \\
\hline
\end{tabular}

Activity index was calculated as the mean value of net zones of inhibition (mm) against three Aspergillus species. 
Table 2: The \% inhibition of the of different plant extracts compared to Griseofulvin (100\% inhibition) against pathogenic Aspergillus species.

\begin{tabular}{|c|c|c|c|c|}
\hline Pathogenic fungus & Griseofulvin & Ethanol & Aqueous & DMSO \\
\hline A. niger & 100 & 57.15 & 114.28 & 100 \\
\hline A. flavus & 100 & 83.34 & 91.67 & 66.67 \\
\hline A. fumigatus & 100 & 72.73 & 81.82 & 90.91 \\
\hline
\end{tabular}

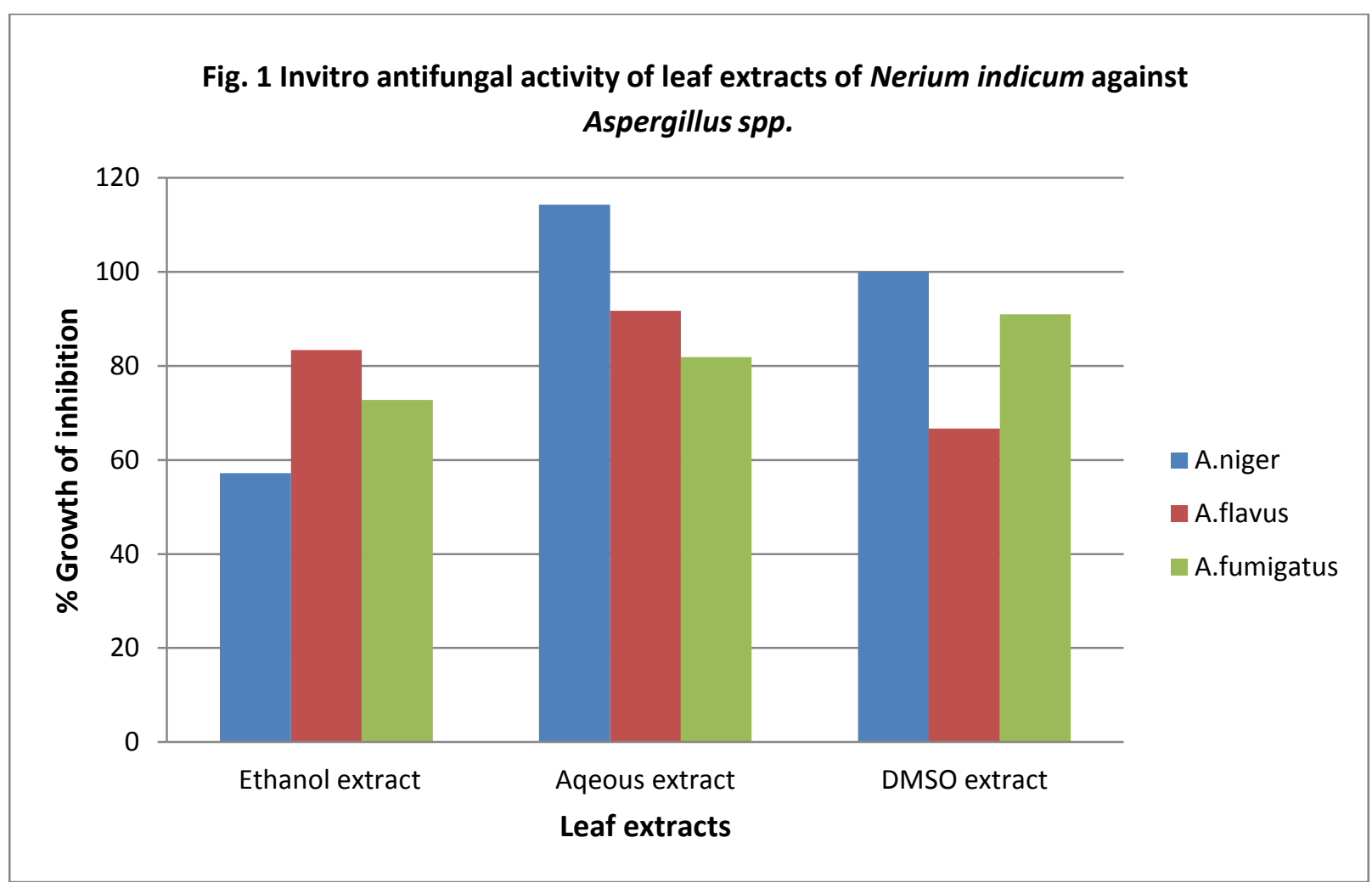

\section{DISCUSSION}

Plants have provided a source of inspiration for novel drug compounds as plant derived medicines have made significant contribution towards human health. It's important to investigate scientifically those plants which have been used in traditional medicines as potential sources of novel antimicrobial compounds [12]. Phytomedicines can be used for the treatment of diseases as is done in case of Unani and Ayurvedic system of medicines or it can be the base for the development of a medicine a natural blueprint for the development of new drugs [13]. In our study we found that leaf extracts of Nerium indicum demonstrated strong antifungal activity on Aspergillus species. Antifungal activity of leaf extracts (ethanol, aqueous and DMSO) were representing in table 1. Better antifungal activity was observed against A.niger with aqueous extract (zone diameter of $16 \mathrm{~mm}$ ) as compared standard (zone diameter of $14 \mathrm{~mm}$ ). The antifungal activities of the leaf extract obtained using different solvent were compared with that of Griseofulvin and the \% of inhibition was calculated. (Table 2).

\section{CONCLUSION}

The eventual conclusion of this study supports the traditional medicine use of leaf extracts in treating different infections caused by pathogenic Aspergillus fungi. Currently microbial infectious have become an important clinical threat, with significant associated morbidity and mortality which is mainly due to the development of microbial resistance to existing of 
microbial agents [14]. As a positive control in our study, the leaf extracts of Nerium indicum demonstrated influential activity against Aspergillus species.

\section{ACKNOWLEDGMENT}

The authors are grateful to Dr. Rama Rani Jain for confirming the identify of plant and Aspergillus sp. We are also thankful to Department of Botany, Samrat Prithviraj Chauhan Govenrment College Ajmer, Rajasthan. For providing facilities and CSIRJRF for providing financial support.

\section{REFERENCES}

[1]. Scorzoni L., Benaducci T., Fusco-Almeida A. M., Siqueira Silva D. H., Silva-Bolzani V., Mendes-Gianinni M. J. S. The use of standard methodology for determination of antifungal activity of natural products against medical yeasts Candida sp. And Cryptococcus sp. Brazilian Journal of Microbiology, 38:391-397, 2007.

[2]. Davies, J. Inactivation of antibiotic and the dissemination of resistance genes. Sci., 264: 375-382, 1994.

[3]. Fleming, R.V., Walsh, T.J., Anaissie, E.J. Emerging and less common fungal pathogens. Infectious Disease Clinics of North America 16, 915933, 2002.

[4]. Walsh, T.J., Groll, A. H. Emerging fungal pathogens: evolving challenges to immunocompromised patients for the twenty-first centuary. Transplant Infectious Disease 1, 247-261, 1992.

[5]. Clardy, J. ; Walsh, C. Lessons from natural molecules. Nature, 432(7019): 829-37, 2004.

[6]. Bhadauria S., and Kumar P. In vitro antimycotic Activity of Some Medicinal Plants Against Human Pathogenic Dermatophytes. Indian journal of fundamental and Applied Life Sciences 2231-6345, 2011.

[7]. Anjana S, Rani V, Padmini R : Antibacterial activity of some medicinal plants used by Tribals against UTI causing pathogens. Wo Appl Sci J $2009 ; 7 ; 332-339$.

[8]. Webster D., Taschereau P., Belland R.J., Sand c., Rennie R.P. Antifungal activity of medicinal plant extracts; preliminary screening studies, 2007.

[9]. Hadizadeh I, Peivastegan B, Kolahi M. Antifungal activity of nettle (Urtica dioica L.), colocynth (Citrullus colocynthis L. Schrad), oleander (Nerium oleander L.) and Konar (Zizyphus spina-christi L) extracts on plants pathogenic fungi. Pak J Biol Sci. 2009; 12:58-63. [PubMed] [Google scholar].

[10]. Balandrin M F, Klocke JA, Wurtele E S and Bollinger W H: Natural plant chemicals: Sources of industrial and Medicinal materials. Science $1985 ; 228: 1154-1160$.

[11]. Alzoreky N S, Nakahara K: Antibaterial activity of extracts from some edible plants commonly consumed in Asia. Int J Food Microbial 2003; $80 ; 223-230$.

[12]. Mitscher, L.A., S. Drake, S.R. Gollapudi and S.K. Okwute. A modern look at folkloric use of anti-infective agents. J. Natural Products, 50: 1025-1040, 1987.

[13]. Jawed, S. and M. Ali. Antimicrobial activity in higher plants, Hamdard medicuse, 45:71-74, 2002.

[14]. Balouiri M., Sadiki M., Ibnsouda S. K. Methods for invitro evauading antimicrobial activity: A review. Journal of Pharmaceutical Analysis.7179, 2016.

\section{Author's profile}

Ms. Renu Jangid is a research scholar, Department of Botany, Samrat Prithviraj Chauhan Goverment College Ajmer, Rajasthan, India. She has completed M.sc. Degree in Botany from Samrat Prithviraj Chauhan Goverment College Ajmer, Rajasthan, India.

Dr. Tahira Begum is currently working as Associate Proffessor, Department of Botany, Samrat Prithviraj Chauhan Government College Ajmer, Rajasthan, India. She has awarded with a Ph.D degree in Botany from Maharshi Dayanand Saraswati University, Ajmer, Rajasthan, India. 